\title{
Increased asthma medication use in association with ambient fine and ultrafine particles
}

\author{
S. von Klot*, G. Wölke*, T. Tuch", J. Heinrich*, D.W. Dockeryף, J. Schwartz " W.G. Kreyling ${ }^{+}$, \\ H.E. Wichmann*,\#, A. Peters*,\#
}

Increased asthma medication use in association with ambient fine and ultrafine particles. S. von Klot, G.Wölke, T. Tuch, J. Heinrich, D.W. Dockery, J. Schwartz, W.G. Kreyling, H.E. Wichmann, A. Peters. C ERS Journals Ltd 2002.

ABSTRACT: The association between particulate air pollution and asthma medication use and symptoms was assessed in a panel study of 53 adult asthmatics in Erfurt, Germany in winter 1996/1997.

Number concentrations of ultrafine particles, $0.01-0.1 \mu \mathrm{m}$ in diameter (NC0.01-0.1), mean $17,300 \cdot \mathrm{cm}^{-3}$, and mass concentrations of fine particles $0.01-2.5 \mu \mathrm{m}$ in diameter (MC0.01-2.5), mean $30.3 \mu \mathrm{g} \cdot \mathrm{m}^{-3}$, were measured concurrently. They were not highly correlated $(r=0.45)$. The associations between ambient particle concentrations and the prevalence of inhaled $\beta_{2}$-agonist, corticosteroid use and asthma symptoms, were analysed separately with logistic regression models, adjusting for trend, temperature, weekend, holidays, and first order autocorrelation of the error.

Cumulative exposures over 14 days of ultrafine and fine particles were associated with corticosteroid use. $\beta_{2}$-agonist use was associated with 5-day mean $\mathrm{NC}_{0.01-0.1}$ and MC0.01-2.5. The prevalence of asthma symptoms was associated with ambient particle concentrations. The results suggest that reported asthma medication use and symptoms increase in association with particulate air pollution and gaseous pollutants such as nitrogen dioxide.

Eur Respir J 2002; 20: 691-702.

\begin{abstract}
*GSF - National Research Center for Environment and Health, Institute of Epidemiology, Neuherberg, Germany, ${ }^{\#}$ Ludwig-Maximilians-University of Munich, Chair of Epidemiology, Institute of Medical Informatics, Biometry and Epidemiology, Munich, Germany, Harvard School of Public Health, Dept of Environmental Health, Boston, MA, USA, ${ }^{+}$GSF - National Research Center for Environment and Health, Institute of Inhalation Biology, Neuherberg, Germany.
\end{abstract}

Correspondence: S. von Klot, GSF Institute of Epidemiology, P.O. Box 1129, D-85758 Neuherberg, Germany. Fax: 498931873380

E-mail: klot@gsf.de

Keywords: Asthma symptoms, inhaled $\beta_{2}$-agonists, inhaled corticosteroids, particulate air pollution, wheezing

Received: August 212001

Accepted after revision: April 22002

This study was funded by: GSF funding, HEI funding Contract 95/10, and EU funding ENV4-CT960205.
Adverse health effects of particulate air pollution, such as increases in mortality and morbidity, have been consistently observed in epidemiological studies at current concentrations [1, 2]. Asthmatics were considered a susceptible population in panel-based, time-series analyses. Small but consistent increases in respiratory symptoms and decreases in lung function were observed in asthmatic adults and children in most of the studies [3-8]. In contrast, a large European multicentre study (Pollution Effects on Asthmatic Children in Europe (PEACE)) has shown negative findings [9]. Asthma medication use has been reported to increase in association with particulate air pollution $[5,10-12]$.

In eastern Germany, air pollution emission has changed substantially since the unification in 1990. Domestic coal heating was replaced by controlled combustion of natural gas or oil. Industrial activity has been reduced and motor vehicle engines improved. The particle size composition in Erfurt, eastern Germany, has been monitored since 1991. Continuous measurements of ambient particulate matter $<10 \mu \mathrm{m}$ in aerodynamic diameter (PM10), fine particles $<2.5 \mu \mathrm{m}$ in aerodynamic diameter (PM2.5), size distribution of particles between $0.01-2.5 \mu \mathrm{m}$ and gases have been conducted. In the past decade, a downward trend of particulate mass and sulphur dioxide $\left(\mathrm{SO}_{2}\right)$ has been observed, but the number concentration of ultrafine particles has remained high [13].

The current regulations of particulate air pollution in the USA and the European Union (EU) aim at the reduction of PM2.5 and PM10 concentrations. These particle fractions are inhaled and have been shown in epidemiological studies to cause adverse health effects $[1,2]$. Also ultrafine particle (diameter $<0.1 \mu \mathrm{m})$ number concentrations have been associated with a decrease of peak expiratory flow (PEF) in panel studies on asthmatic adults in Erfurt [14] and Finland [15] and an increase in symptoms in Erfurt [14]. Furthermore, an increase in mortality was found in association with the number concentration of ultrafine particles (NC0.01-0.1) [16]. These ultrafine particles are present in large numbers, but contribute little mass, therefore they are not controlled by the present regulations. 
The present study aimed to verify of the results observed by PETERs et al. [14] in a larger panel of asthmatic adults and to extend the number of analysed pollutants and health endpoints. The role of ambient air pollution on the increase of medication use was specifically studied. It was hypothesised that elevated concentrations of fine particle mass and number of ultrafine particles are associated with an increase in asthma medication use prevalence. In particular, it was hypothesised that particles may affect on demand medication. Furthermore, the present study investigated whether asthma medication would prevent the reporting of wheezing and other asthma symptoms.

\section{Materials and methods}

\section{Study design}

A panel study was conducted from September 1996-March 1997 in Erfurt, an eastern German city with 200,000 inhabitants. The city is located in a valley surrounded by the Thuringian Forest. During winter, inversion might repeatedly trap the air in the valley. The main sources of ambient air pollution are a power plant, vehicle traffic and domestic heating [16].

During the study period, daily concentrations of air pollutants and meteorological data were assessed. At the same time, study participants kept a diary on their health status and medication use.

\section{Panel study}

Sixty-seven asthmatic adults, resident in Erfurt, were recruited by 14 physicians from September through to November 1996. Respiratory diseases were documented by the physician in a short questionnaire. Eligible participants had to be treated with asthma medication during the previous year, and had to be nonsmokers. Written consent was obtained from all participants.

Details on health and smoking status, as well as socio-demographic indicators of the study subjects were obtained through a questionnaire, based on the European Community (EC) respiratory health survey $[17,18]$.

Asthma was defined as present if the referring physician had diagnosed asthma, or if the subjects themselves in the initial questionnaire had reported asthma diagnosis together with symptoms of asthma in the last 12 months. Asthma symptoms included wheezing, shortness of breath at rest, waking up with breathing problems, or coughing without having a cold.

Asthma medication included inhaled short-acting $\beta_{2}$-agonists, inhaled long-acting $\beta_{2}$-agonists, inhaled corticosteroids, cromolyn sodium, theophylline, oral corticosteroids and $\mathrm{N}$-acetylcysteine.

During the study period, the participants put down the severity of symptoms (as none, slight, severe or very severe) and their medication use (name of medication and number of units taken) in a diary every evening. Symptoms to be noted down were: wheezing, shortness of breath, attack of shortness of breath with wheezing, waking up with breathing problems, phlegm and cough. The present study reports in detail on wheezing as a predominantly lower respiratory tract symptom that is asthma related; the main results of the other symptoms are presented.

Study participants also recorded hours spent outside the study area. The diaries were sent to the research centre every 2 weeks, where they were checked for plausibility and missing values.

Persons who had participated $<30$ days $(n=3)$, reported implausible values $(n=1)$, were found to be active smokers $(n=7)$ or were chronic obstructive pulmonary disease (COPD) patients $(n=3)$ were excluded from the statistical analyses.

\section{Exposure}

Air pollutants and weather data were measured daily in Erfurt. The measurement site is situated in an urban area (background site), $50 \mathrm{~m}$ away from the vehicle traffic [14, 19]. Number concentrations of particles with a diameter between $0.01-2.5 \mu \mathrm{m}$ were measured with a Mobile Aerosol Spectrometer (MAS) in $10 \mathrm{~min}$ intervals $[19,20]$. The MAS consists of two instruments. The first one is a combination of a differential mobility analyser (DMA, model 3071; TSI, Aachen, Germany) and a condensation particle counter (CPC, model 3760; TSI, Aachen, Germany) covering the particle size range $0.01-0.5 \mu \mathrm{m}$; and the second one is an optical laser aerosol spectrometer (Model LAS-X; PMS, Leonberg, Germany), characterising particles ranging in size from $0.1-2.5 \mu \mathrm{m}$. The MAS provides number concentration data as a function of the particle diameter. The mass distribution was estimated on the basis of the volume distribution, assuming spherical particles and a mean density of $1,530 \mathrm{~kg} \cdot \mathrm{m}^{-3}$.

Daily means of the number concentrations were calculated. For regression analyses, the discrete fractions of ultrafine particles (diameter $0.01-0.1 \mu \mathrm{m}$ ), accumulation mode particles (diameter $0.1-0.5 \mu \mathrm{m}$ ) and particles with a diameter between $0.5-2.5 \mu \mathrm{m}$ were chosen [14]. Mass concentrations of fine particles (diameter $<2.5 \mu \mathrm{m}, \mathrm{MC} 0.01-2.5$ ) and of accumulation mode particles (diameter $0.1-0.5 \mu \mathrm{m}, \mathrm{MC} 0.1-0.5$ ) were computed, based on the number concentrations as described above.

PM10 and PM2.5 24-hr measurements were conducted daily with Harvard Impactors. The coarse particle mass fraction (PM2.5-10) was calculated as the difference of these two measurements. PM2.5 daily values highly correlated with the calculated MC0.01-2.5 24-hr means ( $\mathrm{r}=0.97)$ and are therefore not reported.

Measurements of $\mathrm{SO}_{2}\left(\mathrm{SO}_{2}\right.$-monitor, Environment $\mathrm{SA}$, model AF21M), according to the principle of UVfluorescence, temperature and ambient humidity were concurrently conducted at the same site. A monitoring station run by the "Thüringer Landesanstalt für Umwelt" (Thuringian State Institute for Environment) provided data of the daily concentrations of 
nitrogen dioxide $\left(\mathrm{NO}_{2}\right)$ (via chemiluminescence) and carbon monoxide $(\mathrm{CO})$ (on the principle of infra-red light absorption) measured at an urban background station, $\sim 2 \mathrm{~km}$ from the National Research Center for Environment and Health (GSF) measurement station.

\section{Statistical analyses}

Logistic regression models were used to estimate the association between the daily prevalence of medication use as well as symptoms and particulate air pollution controlling for time varying confounders.

Asthma medication categories "inhaled short-acting $\beta_{2}$-agonists" and "inhaled corticosteroids" (including Cromolyn sodium) were formed and coded as 0 (no use of medication) or 1 (use of medication). Daily prevalences of the medications were calculated in the subgroups of participants who, during the study period, ever reported using this medication. Severe or very severe symptoms were classified as a positive response of the respective subject on that day. The daily prevalence of each symptom was calculated based on all participants. Participants who spent $>8 \mathrm{~h}$ outside the study area were excluded from the prevalence calculation of a day. Days for which $<50 \%$ of medication use or symptom data were available were excluded from the analyses, in order to avoid an effect of the recruitment period. Figure 1 shows three respective time series of prevalences as used in the analyses. For the statistical analyses, the number of available days ranged between 131-148, due to missing days in the outcome, exposure and confounder variables.

The selection of the confounders was conducted in stages [21]. Trend was considered as a linear, quadratic or cubic function, to control for an overall increase or decrease, or for seasonal variation in medication use or symptom prevalences. In addition, nonlinearity of trend was assessed using nonparametric methods. Short-term effects of meteorological factors, such as relative humidity and temperature (both as linear and quadratic terms) were considered, and 1-day lags of both were tested. Very cold days $\left(<-10^{\circ} \mathrm{C}\right)$ were additionally adjusted with a piece-wise linear term. Dummy variables for the day of the week were included. An alternative approach distinguished between weekdays and weekends. Dummy variables for each month, Christmas holidays and periods of influenza epidemics were tested. The lack of independence caused by the repeated measures on each subject was considered in the analysis using autoregressive models [22-24]. The models were based on generalised estimating equations, and controlled for heteroscedasticity of the rates [25]. A first-order autoregressive structure was detected. The final model, initially selected for inhaled short-acting $\beta_{2}$-agonists as outcome variable, controlled for first order autoregression, trend (cubic), temperature, weekend, and Christmas holidays, it was verified for the other outcomes that were considered in the analyses. The model was selected stepwise using a combination of goodness-of-fit and change-in-estimate criteria, with a linear trend function as forced in variable.
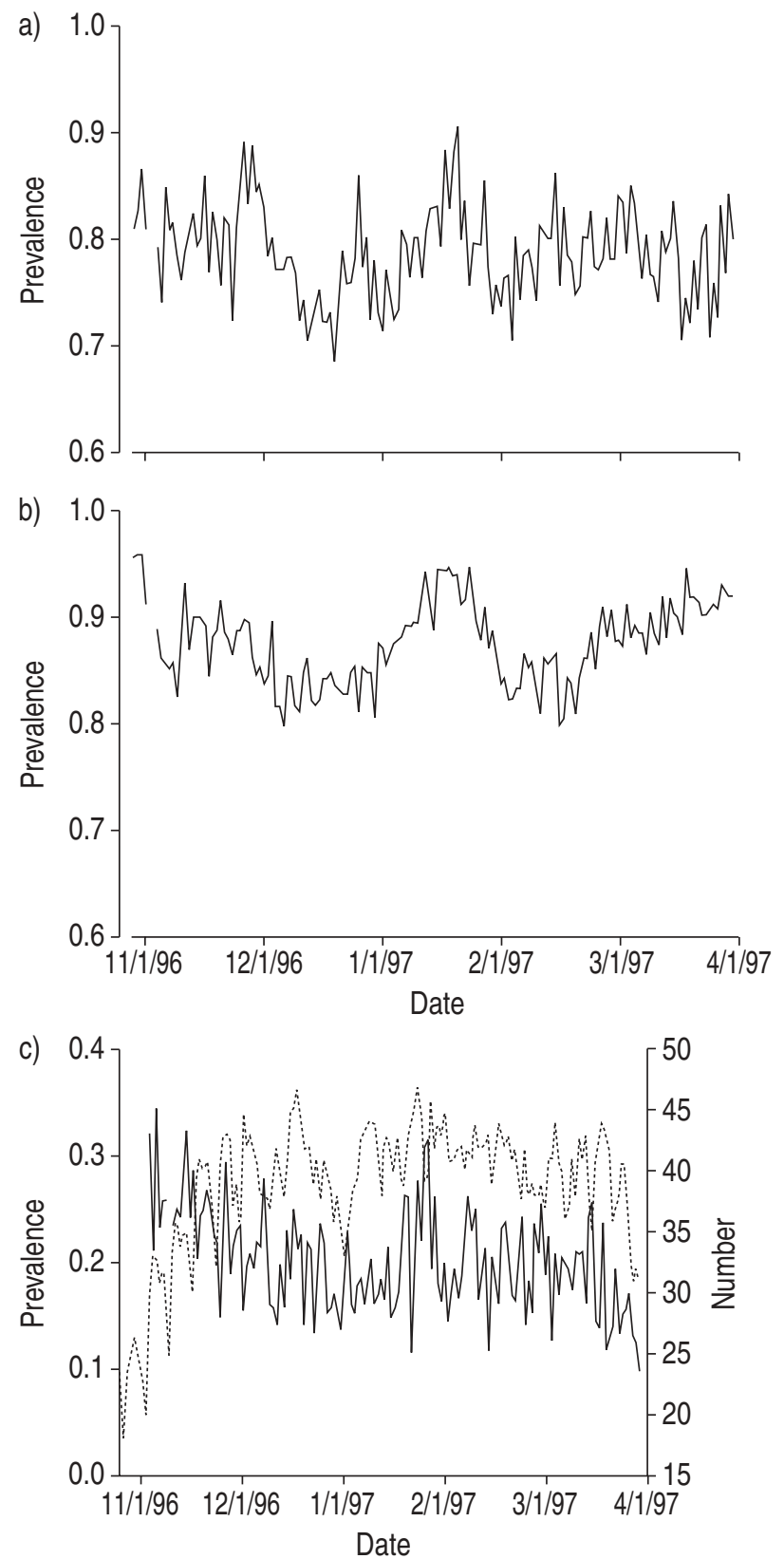

Fig. 1.-Time series of medication use and wheezing prevalence October 25, 1996-March 30, 1997, where participation was $>50 \%$. a) Short-acting $\beta_{2}$-agonist use, b) corticosteroid use, and c) wheezing $(-)$ and participants filling out a diary $(\cdots \ldots \ldots \ldots)$

Since pollution data tend to be serially correlated and since there is a possibility of lagged or accumulated effects, the lag structure was assessed with unconstrained lag models [26]. Moving averages were used in the final models, which were calculated from the same day and the preceding days. The calculation was based on at least two-thirds of nonmissing pollutant measures. Since there was access to exposure data of 2 weeks prior to the analysis period, the number of missing values did not increase with this procedure, when compared to same day exposure measures.

Two-pollutant models were calculated for fine particles (MC0.01-2.5) and for ultrafine particles ( $\mathrm{NC} 0.01-0.1)$, together with the gases $\mathrm{NO}_{2}, \mathrm{SO}_{2}$ and $\mathrm{CO}$. There was 
not sufficient power to distinguish between measures of mass concentrations, given their high correlation. A cut-off point for the correlation coefficient was set at 0.8 , to avoid extreme colinearity, which would cause disproportionately biased effect estimates.

\section{Results}

Final analyses included a total of 53 subjects, 33 were female, average age was $59.0 \mathrm{yrs}$; the range was 37-77 yrs (table 1).

All 53 study participants received asthma medication prescriptions during the study period. Mean prevalence of any medication use was $95.2 \%$, with a minimum of $89.5 \%$ and a maximum of $100 \%$. Most of the asthmatics took inhaled corticosteroids $(n=44)$ combined with theophylline and/or inhaled shortacting $\beta_{2}$-agonists $(n=42)$. Five subjects took only inhaled corticosteroids or theophylline or inhaled short-acting $\beta_{2}$-agonists, respectively; three took a combination of theophylline and inhaled short-acting $\beta_{2}$-agonists. In total, 42 subjects reported use of inhaled short-acting $\beta_{2}$-agonists (tables 1 and 2 ). Figure 1 presents the time series of the prevalence of inhaled medication use during the study period.

On average, $20 \%$ of the adult participants reported wheezing on any given day (table 2). The daily prevalence of wheezing ranged between $10-34 \%$ (fig. 1). Table 2 shows the distribution of prevalence of other symptoms.

Table 1. - Characteristics of the study population

Patient characteristics

\begin{tabular}{lc}
\hline Number of patients & 53 \\
Age mean yrs & 59.0 \\
Sex M:F & $20: 33$ \\
Atopic status & 25 \\
Respiratory health & \\
$\quad$ Asthma & 37 \\
Asthmatic Symptoms only ${ }^{+}$ & 16 \\
Total & 53 \\
Medication & \\
Inhaled short-acting $\beta_{2}$-agonists & 42 \\
Inhaled corticosteroids & 44 \\
Theophylline & 37 \\
Oral corticosteroids & 8 \\
Any asthma medication & $\S$ \\
Smoking & 53 \\
Nonsmoker & \\
Living with smoker & 53 \\
Occupation & 3 \\
Employed & \\
Unemployed & 12 \\
Pensioner & 9 \\
Others & 27 \\
\hline
\end{tabular}

M: male; F: female. " : Hay fever, allergic skin reactions, allergic reactions on insects or medicine; ": asthma diagnosis, or "asthma" and symptoms given in questionnaire; ${ }^{+}$: wheezing, shortness of breath at rest or waking up with breathing problems or coughing without cold in the last 12 months; ${ }^{\S}$ : inhaled $\beta_{2}$-agonists agonists, inhaled corticosteroids, cromolyn sodium, theophylline, oral corticosteroids or $n$-acetylcysteine.
Subjects participated on average 147 days in the study (minimum 45, maximum 188). After excluding days spent outside the study area, mean contribution to the study was 122 days (minimum 25, maximum 187), corresponding to 41 diaries, completed within the study area on average each day.

\section{Air pollutants}

Mass concentrations of all particle fractions as well as $\mathrm{SO}_{2}$ were elevated between December 1996January 1997 (fig. 2). On 2 days, the US standard for PM10 $\left(150 \mu \mathrm{g} \cdot \mathrm{m}^{-3}\right)$ was exceeded. PM10 average concentration was $45.4 \mu \mathrm{g} \cdot \mathrm{m}^{-3}$ (table 2). Maximum observed fine particles mass concentration (MC0.01-2.5) was $133.8 \mu \mathrm{g} \cdot \mathrm{m}^{-3}$, mean was $30.3 \mu \mathrm{g} \cdot \mathrm{m}^{-3}$ (table 2 ). Accumulation mode particles MC $0.1-0.5$ had an average mass concentration of $24.8 \mu \mathrm{g} \cdot \mathrm{m}^{-3}$, which represents $82 \%$ of all fine particles (table 2 ). Number concentrations of ultrafine particles had an average of 17,300 particles $\cdot \mathrm{cm}^{-3}$, and ranged from 3,272-46,195 particles $\cdot \mathrm{cm}^{-3}$ during the study period. Temperature frequently was $<0^{\circ} \mathrm{C}$ in December and January (fig. 2). At the end of December, there was a very cold period with temperatures $<-10^{\circ} \mathrm{C}$.

Particle mass concentrations and particle number concentrations $>0.1 \mu \mathrm{m}$ where highly correlated (table 3). Fine particle mass and accumulation mode particle mass showed a nearly identical time course $(\mathrm{r}=0.997)$. The correlation between ultrafine particle number concentration and fine particle mass concentration was moderate $(\mathrm{r}=0.45)$, as well as its correlation with $\mathrm{PM} 10$ and $\mathrm{SO}_{2}$ (table 3 ). The correlation of ultrafine particles with $\mathrm{CO}$ and $\mathrm{NO}_{2}$ was stronger $(\mathrm{r}=0.66)$. Temperature was correlated negatively with all pollutants, relative humidity in contrast was positively correlated.

\section{Association between air pollutants and health outcomes}

A delayed response to ambient pollution was investigated and evidence was found in unconstrained lag models. These models suggested considering an accumulation of effects over a period of $\sim 5$ days for inhaled short-acting $\beta_{2}$-agonist use and over $\geqslant 10$ days for inhaled corticosteroid use (fig. 3). To account for this, 5- 10- and 14-day running means were used in the final models. The results for 10-day running means are not shown, as they were very similar to the 14-day mean results.

An example of the effect estimates of the confounders in the multivariate models is as follows: Corticosteroid use increased with falling temperatures (odds ratio $(\mathrm{OR})$ for a decrease of $5^{\circ} \mathrm{C}$, when $>-10^{\circ} \mathrm{C}$ : $1.06(95 \%$ confidence interval $(\mathrm{CI}): 1.00-1.12))$ when including the 14-day moving average of ultrafine particles. No effect of temperature was observed when $<-10^{\circ} \mathrm{C}$ (OR 0.83 ; 95\% CI 0.68-1.02, for e.g. $-12--17^{\circ} \mathrm{C}$ ). Weekends showed a similar medication prevalence as weekdays (OR 1.01; 95\% CI 0.93-1.10), as well as Christmas holidays (OR 1.05; 95\% CI $0.89-1.25)$. 
Table 2. - Distributions of 24-h mean air pollutants, temperature, prevalence of medication use and symptoms between October 25, 1996-March 30, 1997

\begin{tabular}{|c|c|c|c|c|c|c|c|}
\hline & $\mathrm{N}$ days ${ }^{\#}$ & Mean & Minimum & $25 \%$ & Median & $75 \%$ & Maximum \\
\hline \multicolumn{8}{|l|}{ Number concentrations $\mathrm{cm}^{-3}$} \\
\hline NC0.01-0.1 & 145 & 17300 & 3272 & 9286 & 16940 & 24484 & 46195 \\
\hline $\mathrm{NC} 0.1-0.5$ & 147 & 2005 & 291 & 958 & 1610 & 2767 & 6700 \\
\hline NC0.5-2.5 & 141 & 21.4 & 0.9 & 5.6 & 13.0 & 31.6 & 127.6 \\
\hline \multicolumn{8}{|l|}{ Mass concentrations $\mu \mathrm{g} \cdot \mathrm{m}^{-3}$} \\
\hline MC0.1-0.5 & 147 & 24.8 & 2.4 & 11.4 & 19.6 & 33.1 & 108.3 \\
\hline MC0.01-2.5 & 142 & 30.3 & 3.6 & 13.5 & 24.6 & 41.3 & 133.8 \\
\hline PM2.5-10 & 140 & 10.3 & -8.7 & 2.9 & 6.9 & 14.6 & 64.3 \\
\hline PM10 & 148 & 45.4 & 4.7 & 19.6 & 35.0 & 59.7 & 172.4 \\
\hline \multicolumn{8}{|l|}{ Gases } \\
\hline $\mathrm{NO}_{2} \mu \mathrm{g} \cdot \mathrm{m}^{-3}$ & 157 & 46 & 8 & 34 & 45 & 56 & 119 \\
\hline $\mathrm{CO} \mathrm{mg} \cdot \mathrm{m}^{-3}$ & 156 & 0.9 & 0.3 & 0.5 & 0.8 & 1.2 & 3.0 \\
\hline $\mathrm{SO}_{2} \mu \mathrm{g} \cdot \mathrm{m}^{-3}$ & 152 & 24.0 & 0.1 & 8.4 & 15.9 & 29.3 & 114.7 \\
\hline Temperature ${ }^{\circ} \mathrm{C}$ & 152 & 2.6 & -17.3 & -1.2 & 3.0 & 7.9 & 18.7 \\
\hline $\begin{array}{c}\text { Inhaled short-acting } \\
\beta_{2} \text {-agonists }\end{array}$ & 151 & 79 & 69 & 76 & 79 & 81 & 90 \\
\hline Inhaled corticosteroids ${ }^{+}$ & 153 & 88 & 80 & 85 & 88 & 91 & 96 \\
\hline Wheezing $\% §$ & 146 & 20 & 10 & 16 & 20 & 23 & 34 \\
\hline $\begin{array}{l}\text { Attack of shortness of } \\
\text { breath and wheezing }\end{array}$ & 146 & 13 & 3 & 10 & 13 & 17 & 27 \\
\hline $\begin{array}{l}\text { Waking up with breathing } \\
\text { problems }\end{array}$ & 146 & 23 & 9 & 18 & 22 & 26 & 45 \\
\hline Shortness of breath & 146 & 28 & 15 & 23 & 27 & 32 & 47 \\
\hline Phlegm & 146 & 27 & 14 & 24 & 27 & 30 & 44 \\
\hline Cough & 146 & 27 & 11 & 22 & 26 & 31 & 47 \\
\hline
\end{tabular}

Data are presented as \% unless otherwise stated. NC: number concentration of particles (numbers represent diameter of particles in $\mu \mathrm{m}$ ); MC: mass concentration of particles (numbers represent diameter of particles in $\mu \mathrm{m}$ ); PM2.5-10: particulate matter with a 2.5-10 $\mu \mathrm{m}$ aerodynamic diameter; PM10: particulate matter $<10 \mu \mathrm{m}$ in aerodynamic diameter; $\mathrm{NO}_{2}$ : nitrogen dioxide; $\mathrm{CO}$ : carbon monoxide; $\mathrm{SO}_{2}$ : sulphur dioxide. ${ }^{*}$ : maximum number of days was 157 . Lower numbers in the prevalence time series are caused by the rule of excluding days with $<50 \%$ of data; ${ }^{\uparrow}$ : prevalence calculated in the 42 participants who ever reported use of $\beta_{2}$-agonists; ${ }^{+}$: prevalence calculated in the 44 participants who ever reported use of corticosteroids; : prevalence calculated in all 53 participants for symptoms.

Table 4 summarises the results of the prevalence of short-acting $\beta_{2}$-agonists. There was no association of same day values of all pollutants with the prevalence of short-acting $\beta_{2}$-agonists. An association was present with the 5-day running means of almost all subfractions of particles. Only $\mathrm{CO}$ and the coarse particle fraction (PM2.5-10) did not achieve statistical significance. Fourteen-day means of the pollutants mostly had lower, and often not statistically significant effect estimates.

In the two-pollutant models, the 5-day mean ultrafine particle number concentration and fine particle mass concentration appeared to have independent effects on the use of inhaled short-acting $\beta_{2}$-agonists (table 5). $\mathrm{NO}_{2}$ seemed to be the best predictor.

Regression results of inhaled corticosteroid use are shown in table 6 . Positive statistically significant associations were observed between inhaled corticosteroids and same day exposure to ultrafine particle number concentrations, fine particle number concentrations and the gases $\mathrm{NO}_{2}$ and $\mathrm{CO}$. Significant effects were found for 5-day running means of the particle fractions as well as of the gases. Noticeably higher effects were observed in association with the 14-day mean particulate air pollutants. $\mathrm{SO}_{2}$ showed a similar, but not equally strong tendency to longer accumulated effects. $\mathrm{CO}$ and $\mathrm{NO}_{2}$ demonstrated higher effects for the 5-day mean than for the 14-day mean. The magnitude of the associations of inhaled corticosteroid use with fine or ultrafine particles was similar. In the two-pollutant models, 14-day mean NC0.01-0.1 showed a weaker effect than MC0.01-2.5 (table 5). $\mathrm{MC} 0.01-2.5$ showed a stronger association with inhaled corticosteroid use than $\mathrm{CO}$ and $\mathrm{NO}_{2}$.

Regression results of wheezing are shown in table 7. Little evidence was seen for an association between same-day pollutant measures and the prevalence of wheezing. Statistically significant associations between the 5-day mean number concentration of ultrafine particles, $\mathrm{CO}$ and $\mathrm{NO}_{2}$ and the prevalence of wheezing were observed. Positive, but weaker associations were seen with mass concentrations. The observed effects of ultrafine particle and accumulation mode number concentrations increased when considering the 14-day means, but were little changed for particle mass, CO and $\mathrm{NO}_{2}$.

Two-pollutant models, that considered the 5-day means of the pollutants, supported a strong ultrafine particle effect on the prevalence of wheezing (table 5). Ultrafine particles competed for the effect with the gases $\mathrm{CO}$ and $\mathrm{NO}_{2}$, whereas the evidence of a fine particle mass effect remained poor. In the twopollutant model with the 14-day means, there was even stronger evidence of an association of the ultrafine particles with the prevalence of wheezing.

Table 8 shows the main results of the other 

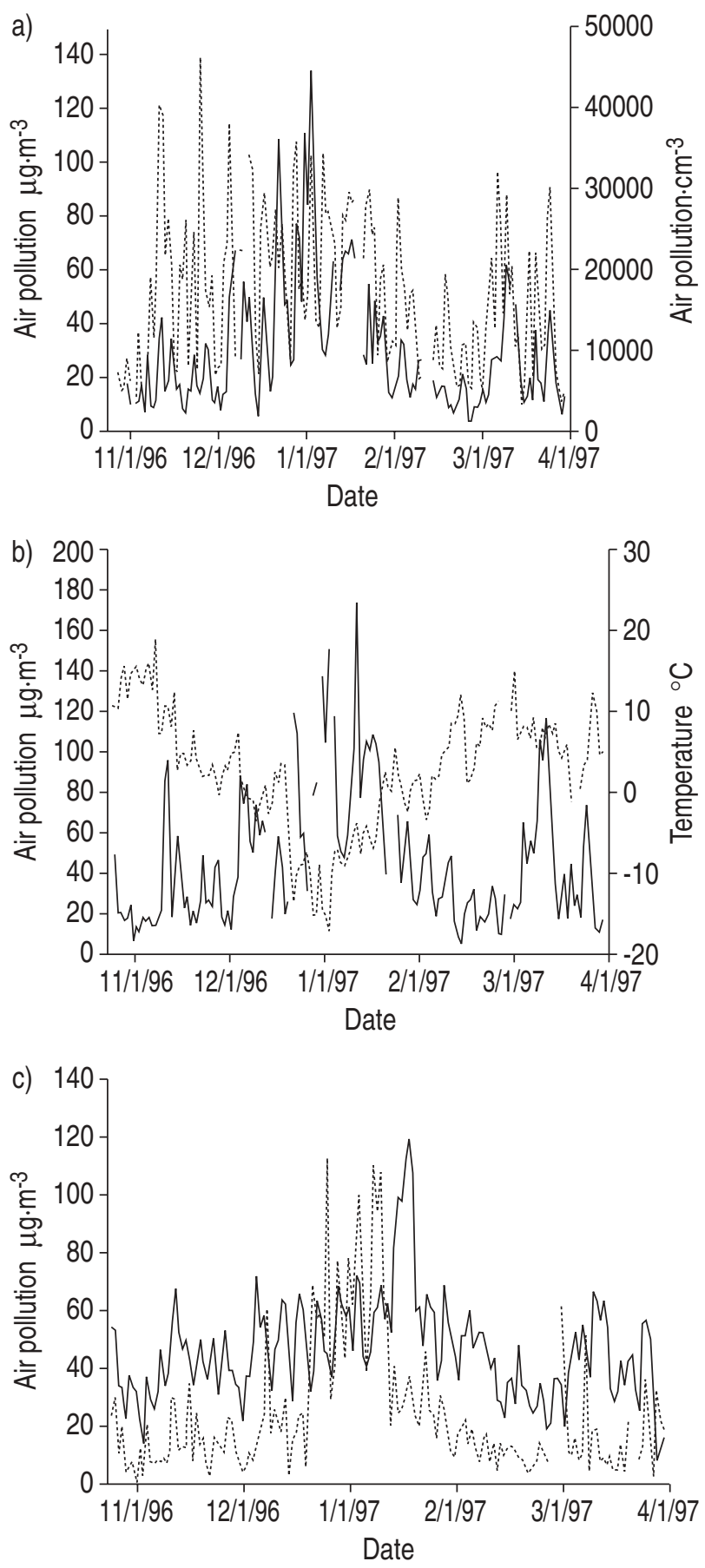

Fig. 2.-Air pollution and temperature in Erfurt, Germany during the winter of 1996-1997. a) Number concentrations of ultrafine particles, $0.01-0.1 \mu \mathrm{m}$ in diameter ( $\mathrm{NC} 0.01-0.1)$ : $\cdots \cdots \cdots \cdots$; mass concentrations of fine particles $0.01-2.5 \mu \mathrm{m}$ in diameter $(\mathrm{MC} 0.01-2.5)$ : b) Particulate matter $<10 \mu \mathrm{m}$ in aerodynamic diameter: - ; Temperature: $\cdots \cdots \cdots \cdot$ c) Nitrogen dioxide $\left(\mathrm{NO}_{2}\right)$ : $\cdots \cdots \cdots \cdot$. Sulphur dioxide $\left(\mathrm{SO}_{2}\right)$ : -

symptoms. Shortness of breath and its combination with wheezing both showed a similar pattern as wheezing, whereas for "waking up with breathing problems" in addition a 5-day mean PM2.5 effect and an immediate $\mathrm{NO}_{2}$ effect were found. Cough and phlegm showed consistent and significant associations with ultrafine and fine particles, as well as with $\mathrm{NO}_{2}$. The effect of 5- and 14-day running means were comparable.

\section{Discussion}

\section{Summary of results}

In the present study, increased inhaled asthma medication use and symptoms of asthma, such as wheezing, were associated with particulate air pollution.

Short-acting $\beta_{2}$-agonist use was associated with 5-day means of pollutants. Nearly all pollutants showed a significant association of a similar magnitude. In twopollutant models, effect estimates of ultrafine particle number concentration and fine particle mass concentration were comparable (fig. 4). Inhaled corticosteroid use in contrast was strongly associated with the 14-day running means of fine and ultrafine particles. In two-pollutant models, the mass concentration of fine particles showed stronger effects than the ultrafine particle number concentration.

The 5- and 14-day average concentrations of ultrafine particles were associated with the prevalence of wheezing. No evidence for an immediate effect was observed. No significant association was seen for mass or number concentrations of fine particles. The gases $\mathrm{CO}$ and $\mathrm{NO}_{2}$ showed a positive association with the prevalence of wheezing. Two-pollutant models underlined the effect of ultrafine particles. Other asthma symptoms showed consistent effects.

\section{Medication use}

The observed association between particulate mass concentrations and inhaled short-acting $\beta_{2}$-agonist use is consistent with other studies, that were conducted in children or adults with respiratory symptoms or asthma [7, 8, 27-31]. Evidence of a cumulative effect of air pollution on medication use has been found [7, 8, 28-31]. However, studies are reported that observed no association between $\beta_{2}$-agonist use and PM10 [32, 33]. Inhaled corticosteroid use was previously analysed within a category of "maintenance medication" [7, 27, 28] or "asthma medication" (including inhaled $\beta_{2}$-agonists and corticosteroids) [5], only two of these showed an association with PM10 [5, 27]. In a study on adult asthmatics, little evidence of an association of inhaled corticosteroids (as separate category) with PM10 and black smoke was observed [29]. An explanation for this might be that this study was conducted in summer, had a shorter follow-up period and lower pollution concentration than the present study.

Inhaled corticosteroids are not an on-demand medication like inhaled short-acting $\beta_{2}$-agonists, they should be used on a regular basis. Hence, with perfect compliance an association between air pollution and inhaled corticosteroids would not be expected. It had been hypothesised that particulate air pollution may particularly affect the use of on-demand medication. In contrast, considerable variation in the use 

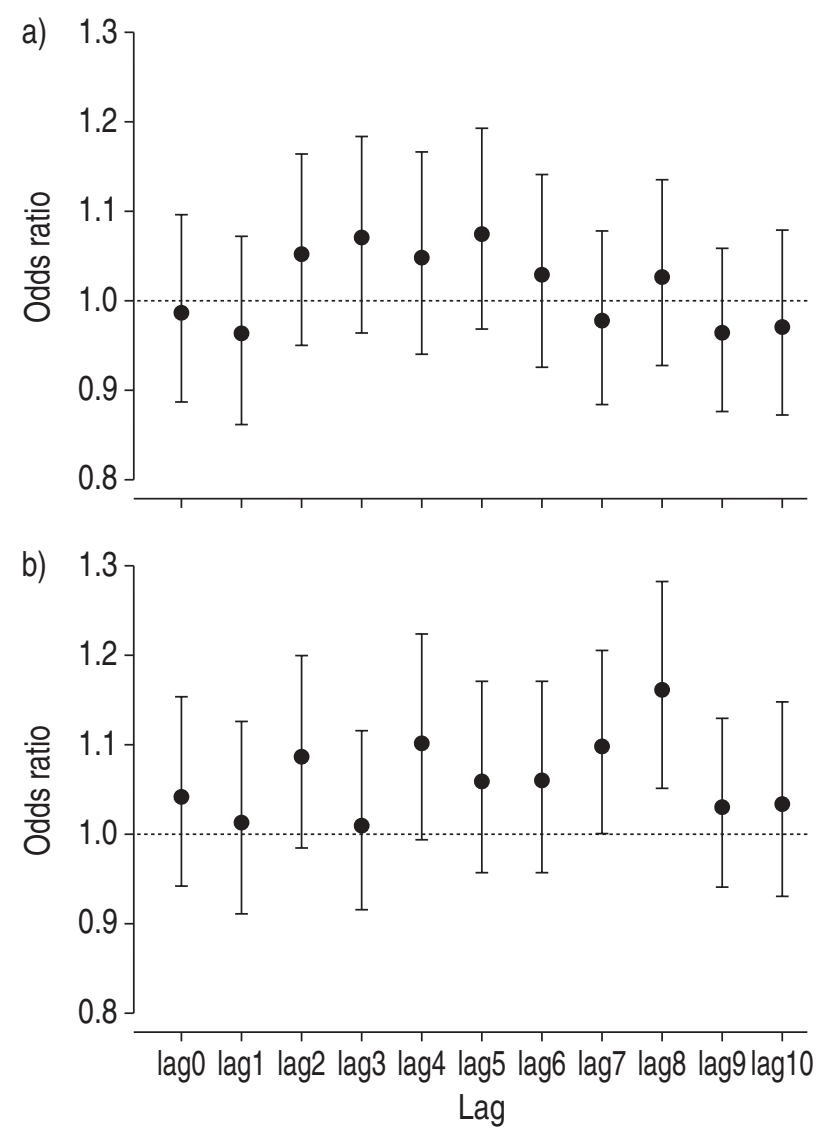

Fig. 3.-Unconstrained lag models of the association between reported medication use and number concentrations of ultrafine particles, $0.01-0.1 \mu \mathrm{m}$ in diameter $(\mathrm{NC} 0.01-0.1)$, lags $0-10$, adjusting for cubic trend, temperature, weekend, Christmas holidays and first-order autocorrelation (odds ratios calculated for increase in one interquartile range). a) Short-acting $\beta_{2}$-agonist use, and b) corticosteroid use.

of corticosteroids was observed; effects of ambient particulate air pollution were higher for the use of corticosteroids than for the use of inhaled $\beta_{2}$-agonists, and accumulated over a more extended period. The unsatisfactory compliance that was observed might be responsible for this phenomenon; patients might stop the usage of their medication when they don't feel ill and restart to inhale when they feel bad due to external stressors, for example after a prolonged period of high air pollution levels.

Unconstrained lag models showed a contribution of the exposure over $>10$ preceding days on the prevalence of corticosteroid use and a shorter cumulated effect on short-acting $\beta_{2}$-agonist use (fig. 3). It is important to note that the individual estimates in these models cannot be readily interpreted due to the high correlation between the individual lags. The present authors considered moving averages that assign equal weights to each lag in the final models in order to overcome this limitation [26]. The largest effect estimates for wheezing and for corticosteroid use were seen with the 14-day running means. This might be explained by a provocation of an inflammatory reaction in association with exposure to accumulated ultrafine particle number concentration. This is in line with NEUKIRCH et al. [34], who found effects of air pollution on symptoms that continued for several days after the exposure, and who suggested that the inflammatory process in the airways was the reason for this.

A key difference between this study and most previous investigations is that the present study examined effects of air pollution with lags $\leqslant 14$ days, rather than just a few days. Had the study used exposure on the same or the previous few days only, the effects seen would have been much weaker. The results were confirmed, when considering nonparametric lag functions of trend. Hence, a key finding of this study is the need to examine longer lags.

\section{Wheezing}

Several studies have analysed the effect of particles and other air pollutants on wheezing within

Table 3. - Pearson's correlation coefficients for the pollutants (same day values) and temperature between October 25, 1996-March 30, 1997 in Erfurt, Germany

\begin{tabular}{|c|c|c|c|c|c|c|c|c|c|c|}
\hline & $\mathrm{NC} 0.1-0.5$ & $\mathrm{NC} 0.5-2.5$ & MC0.1-0.5 & $\mathrm{MC} 0.01-2.5$ & PM2.5-10 & PM10 & $\mathrm{NO}_{2}$ & $\mathrm{CO}$ & $\mathrm{SO}_{2}$ & Temperature \\
\hline \multicolumn{11}{|c|}{ Number concentrations } \\
\hline NC0.01-0.1 & 0.55 & 0.34 & 0.45 & 0.45 & 0.41 & 0.51 & 0.66 & 0.66 & 0.36 & -0.40 \\
\hline $\mathrm{NC} 0.1-0.5$ & & 0.76 & 0.95 & 0.93 & 0.50 & 0.85 & 0.75 & 0.79 & 0.51 & -0.62 \\
\hline $\mathrm{NC} 0.5-2.5$ & & & 0.92 & 0.94 & 0.48 & 0.88 & 0.54 & 0.46 & 0.66 & -0.68 \\
\hline \multicolumn{11}{|c|}{ Mass concentrations } \\
\hline MC0.1-0.5 & & & & 1.00 & 0.51 & 0.91 & 0.69 & 0.66 & 0.60 & -0.71 \\
\hline $\mathrm{MC} 0.01-2.5^{\#}$ & & & & & 0.52 & 0.94 & 0.68 & 0.65 & 0.62 & -0.71 \\
\hline PM2.5-10 & & & & & & 0.67 & 0.45 & 0.42 & 0.28 & -0.27 \\
\hline PM10 & & & & & & & 0.74 & 0.69 & 0.55 & -0.62 \\
\hline \multicolumn{11}{|l|}{ Gases } \\
\hline $\mathrm{NO}_{2}$ & & & & & & & & 0.82 & 0.36 & -0.50 \\
\hline $\mathrm{CO}$ & & & & & & & & & 0.32 & -0.46 \\
\hline $\mathrm{SO}_{2}$ & & & & & & & & & & -0.67 \\
\hline
\end{tabular}

Data are presented as Pearson's correlation coefficients. NC: number concentration of particles (numbers represent diameter of particles in $\mu \mathrm{m}$ ); MC: mass concentration of particles (numbers represent diameter of particles in $\mu \mathrm{m}$ ); PM2.5-10: particulate matter with a 2.5-10 $\mu \mathrm{m}$ aerodynamic diameter; PM10: particulate matter $<10 \mu \mathrm{m}$ in aerodynamic diameter; $\mathrm{NO}_{2}$ : nitrogen dioxide; $\mathrm{CO}$ : carbon monoxide; $\mathrm{SO}_{2}$ : sulphur dioxide. \#: Correlation of MC0.01-2.5 and PM2.5 r=0.97. 
Table 4. - Effect estimates ${ }^{\#}$ for the association between the prevalence of inhaled short-acting $\beta_{2}$-agonists agonist use and particulate and gaseous pollution (odds ratios (OR) and 95\% confidence intervals (Cl) are given for an increase of one interquartile range (IQR))

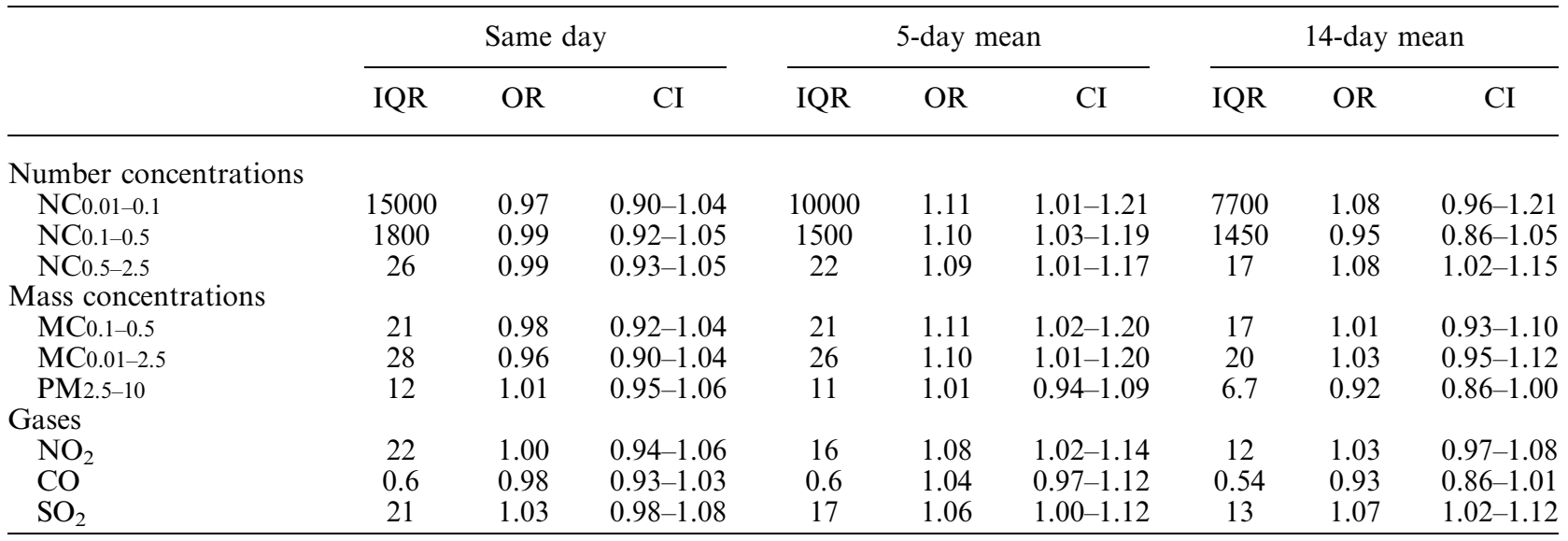

NC: number concentration of particles (numbers represent diameter of particles in $\mu \mathrm{m}$ ); MC: mass concentration of particles (numbers represent diameter of particles in $\mu \mathrm{m}$ ); $\mathrm{PM} 2.5-10$ : particulate matter with a 2.5-10 $\mu \mathrm{m}$ aerodynamic diameter; $\mathrm{NO}_{2}$ : nitrogen dioxide; $\mathrm{CO}$ : carbon monoxide; $\mathrm{SO}_{2}$ : sulphur dioxide. ${ }^{\#}$ : Adjusted for cubic trend, temperature, weekend, Christmas holidays, first order autocorrelation. Analysis period October 29, 1996-March 30, 1997 (153 days).

the "lower respiratory symptoms" category. An association with elevated PM10 concentrations was observed in symptomatic children $[4,5,28,31]$. In other recent studies, however, PM10 showed no effect on lower respiratory symptoms in adults [32] and children [9, 33, 35] (PEACE study). In the PEACE study, the short follow-up period made it difficult to control for seasonal or other time trends. This study, with a longer follow-up had less difficulty in this regard.

Significant effects of $\mathrm{PM} 10, \mathrm{SO}_{2}$ and $\mathrm{NO}_{2}$ on the prevalence of wheezing as a separate outcome were observed in asthmatic adults [34]. Associations of $\mathrm{PM} 10, \mathrm{SO}_{2}$ and black smoke with wheezing were found in children [7]. Other studies did not observe significant associations between wheezing and particulate matter (PM10, PM2.5) [27, 30], or gases $\left(\mathrm{NO}_{2}\right.$, $\mathrm{SO}_{2}$ ) [30].

Only one study, in which wheezing was aggregated together with breathlessness in an asthma symptom category, considered ultrafine particle number concentrations as well as PM2.5 and PM10 as exposures [15]. This study, which had been conducted in Finland, showed effects of ultrafine particles on peak expiratory flow (PEF), but in contrast to the present study, no effects on the symptoms (including wheezing).

Table 5. - Effect estimates ${ }^{\#}$ of the association between two pollutants, jointly in one model, and the health outcomes (odds ratios $(\mathrm{OR})$ and $95 \%$ confidence intervals $(\mathrm{Cl})$ are given for an increase of one interquartile range (IQR) as specified in table 4)

\begin{tabular}{|c|c|c|c|c|c|c|c|c|}
\hline \multirow[t]{2}{*}{ Prevalence of } & \multicolumn{2}{|c|}{ Pollutant } & \multicolumn{2}{|c|}{$\mathrm{MC} 0.01-2.5$} & \multicolumn{2}{|c|}{ Pollutant } & \multicolumn{2}{|c|}{ NC0.01-0.1 } \\
\hline & OR & $\mathrm{CI}$ & OR & $\mathrm{CI}$ & OR & CI & OR & CI \\
\hline \multicolumn{9}{|c|}{ Inhaled short-acting $\beta_{2}$-agonist use } \\
\hline NC0.01-0.1 & 1.07 & $0.97-1.18$ & 1.07 & $0.98-1.18$ & & & & \\
\hline $\mathrm{NO}_{2}$ & 1.10 & $1.02-1.19$ & 1.00 & $0.89-1.12$ & 1.09 & $1.02-1.18$ & 1.01 & $0.90-1.13$ \\
\hline $\mathrm{CO}$ & 1.00 & $0.91-1.11$ & 1.10 & $0.98-1.22$ & 1.01 & $0.91-1.11$ & 1.10 & $0.98-1.25$ \\
\hline $\mathrm{SO}_{2}$ & 1.05 & $0.99-1.11$ & 1.07 & $0.98-1.17$ & 1.06 & $1.00-1.12$ & 1.08 & $0.99-1.19$ \\
\hline \multicolumn{9}{|c|}{ Inhaled corticosteroid use ${ }^{+}$} \\
\hline NC0.01-0.1 & 1.01 & $0.87-1.18$ & 1.53 & $1.39-1.69$ & & & & \\
\hline $\mathrm{NO}_{2}$ & 1.02 & $0.95-1.10$ & 1.51 & $1.35-1.68$ & 1.19 & $1.07-1.32$ & 1.06 & $0.85-1.32$ \\
\hline $\mathrm{CO}$ & 0.89 & $0.81-0.98$ & 1.63 & $1.49-1.78$ & 0.81 & $0.72-0.91$ & 1.82 & $1.54-2.15$ \\
\hline $\mathrm{SO}_{2}$ & \multicolumn{4}{|c|}{ Correlation coefficient larger than 0.8} & 1.24 & $1.19-1.29$ & 1.28 & $1.15-1.44$ \\
\hline \multicolumn{9}{|c|}{ 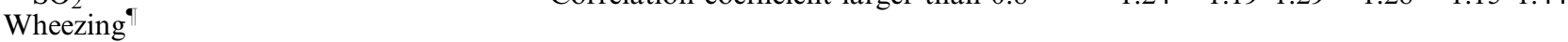 } \\
\hline NC0.01-0.1 & 1.12 & $1.01-1.24$ & 1.02 & $0.92-1.12$ & & & & \\
\hline $\mathrm{NO}_{2}$ & 1.05 & $0.97-1.14$ & 1.01 & $0.89-1.15$ & 1.01 & $0.94-1.09$ & 1.12 & $0.99-1.26$ \\
\hline $\mathrm{CO}$ & 1.15 & $1.04-1.27$ & 0.96 & $0.86-1.08$ & 1.09 & $0.98-1.22$ & 1.05 & $0.92-1.19$ \\
\hline $\mathrm{SO}_{2}$ & 0.97 & $0.91-1.04$ & 1.09 & $0.99-1.20$ & 0.97 & $0.92-1.03$ & 1.14 & $1.04-1.26$ \\
\hline
\end{tabular}

NC: number concentration of particles (numbers represent diameter of particles in $\mu \mathrm{m}$ ). $\mathrm{NO}_{2}$ : nitrogen dioxide; CO: carbon monoxide; $\mathrm{SO}_{2}$ : sulphur dioxide; $\mathrm{MC}$ : mass concentration of particles (numbers represent diameter of particles in $\mu \mathrm{m}$ ); ${ }^{\#}$ : adjusted for cubic trend, temperature, weekend, Christmas holidays, first order autocorrelation; " : air pollution exposures: 5-day means; ${ }^{+}$: air pollution exposures: 14-day means. 
Table 6. - Effect estimates ${ }^{\#}$ for the association between the prevalence of inhaled corticosteroid use and particulate and gaseous pollution (odds ratios (OR) and $95 \%$ confidence intervals $(\mathrm{Cl})$ are expressed for an increase of one interquartile range (IQR))

\begin{tabular}{|c|c|c|c|c|c|c|c|c|c|}
\hline & \multicolumn{3}{|c|}{ Same day } & \multicolumn{3}{|c|}{ 5-day mean } & \multicolumn{3}{|c|}{ 14-day mean } \\
\hline & IQR & OR & CI & IQR & OR & CI & IQR & OR & CI \\
\hline \multicolumn{10}{|c|}{ Number concentrations } \\
\hline NC0.01-0.1 & 15000 & 1.07 & $1.00-1.15$ & 10000 & 1.22 & $1.12-1.33$ & 7700 & 1.45 & $1.29-1.63$ \\
\hline $\mathrm{NC} 0.1-0.5$ & 1800 & 1.06 & $0.99-1.14$ & 1500 & 1.23 & $1.14-1.32$ & 1450 & 1.51 & $1.37-1.67$ \\
\hline $\mathrm{NC} 0.5-2.5$ & 26 & 1.13 & $1.06-1.21$ & 22 & 1.28 & $1.19-1.37$ & 17 & 1.44 & $1.36-1.53$ \\
\hline \multicolumn{10}{|c|}{ Mass concentrations } \\
\hline MC0.1-0.5 & 21 & 1.09 & $1.02-1.17$ & 21 & 1.28 & $1.18-1.39$ & 17 & 1.49 & $1.38-1.61$ \\
\hline MC0.01-2.5 & 28 & 1.10 & $1.02-1.18$ & 26 & 1.28 & $1.18-1.39$ & 20 & 1.54 & $1.43-1.66$ \\
\hline $\mathrm{PM}_{2.5-10}$ & 12 & 1.03 & $0.98-1.08$ & 11 & 1.12 & $1.04-1.20$ & 6.7 & 1.27 & $1.18-1.37$ \\
\hline \multicolumn{10}{|l|}{ Gases } \\
\hline $\mathrm{NO}_{2}$ & 22 & 1.15 & $1.09-1.23$ & 16 & 1.29 & $1.22-1.37$ & 12 & 1.21 & $1.15-1.28$ \\
\hline $\mathrm{CO}$ & 0.6 & 1.05 & $1.00-1.11$ & 0.6 & 1.25 & $1.17-1.34$ & 0.54 & 1.06 & $0.97-1.15$ \\
\hline $\mathrm{SO}_{2}$ & 21 & 1.03 & $0.98-1.09$ & 17 & 1.21 & $1.14-1.28$ & 13 & 1.28 & $1.22-1.33$ \\
\hline
\end{tabular}

NC: number concentration of particles (numbers represent diameter of particles in $\mu \mathrm{m}$ ); MC: mass concentration of particles (numbers represent diameter of particles in $\mu \mathrm{m}$ ); $\mathrm{PM} 2.5-10$ : particulate matter with a 2.5-10 $\mu \mathrm{m}$ aerodynamic diameter; $\mathrm{NO}_{2}$ : nitrogen dioxide; $\mathrm{CO}$ : carbon monoxide; $\mathrm{SO}_{2}$ : sulphur dioxide. ${ }^{\#}$ : adjusted for cubic trend, temperature, weekend, Christmas holidays, first order autocorrelation. Analysis period October 25, 1996-March 30, 1997 (157 days).

Here, the symptom wheezing has been specifically discussed, but remarkably consistent effects on other asthma symptoms were also detected.

\section{Asthma symptoms and medication}

Asthma medication might be a confounder or effect modifier of the association between air pollution and asthma. In an epidemiological study of patients with severe asthma, pulmonary function increased when particulate matter exposure was elevated [10]. This was interpreted as confounding by medication. In asthmatic children the association between symptoms and particulate air pollution was modified by medication use [11]. In a stratified analysis of asthmatic adults, the subgroup that regularly inhaled shortacting $\beta_{2}$-agonist, showed no effects, whereas variably medicated subjects showed adverse health effects of pollutants [34]. Recent studies showed that in children the adverse effects of particulate air pollution could not be prevented by medication $[11,12,31]$. In the present study, an association of ultrafine particles with asthma symptoms was observed, although there was an increased use of inhaled short-acting $\beta_{2}$-agonists and corticosteroids with elevated ultrafine particle number concentrations. Thus, the effect estimates for particulate air pollution on, for example, wheezing might be underestimated. An effect of fine particle mass on wheezing was not detectable, because it might have been effectively compensated by the inhaled corticosteroids.

Table 7. - Effect estimates ${ }^{\#}$ for the association between the prevalence of wheezing and particulate and gaseous pollution (odds ratios $(\mathrm{OR})$ and 95\% confidence intervals $(\mathrm{Cl})$ are expressed for an increase of one interquartile range (IQR))

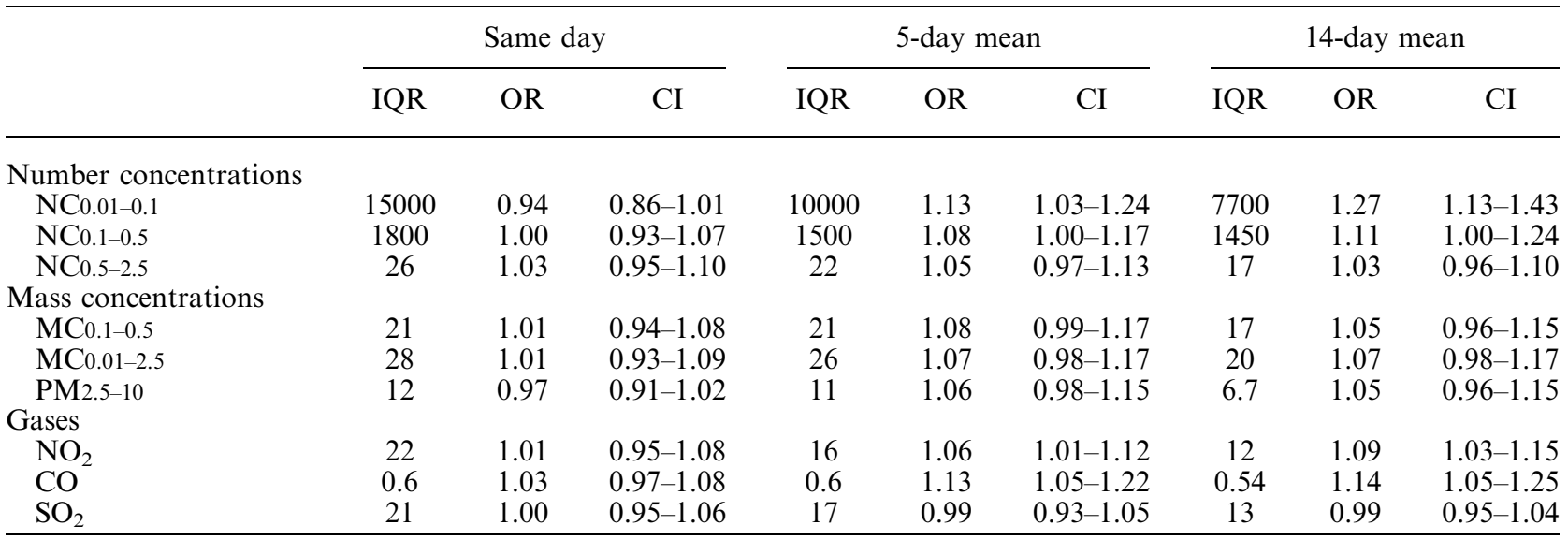

NC: number concentration of particles (numbers represent diameter of particles in $\mu \mathrm{m}$ ); MC: mass concentration of particles (numbers represent diameter of particles in $\mu \mathrm{m}$ ); PM2.5-10: particulate matter with a $2.5-10 \mu \mathrm{m}$ aerodynamic diameter; $\mathrm{NO}_{2}$ : nitrogen dioxide; $\mathrm{CO}$ : carbon monoxide; $\mathrm{SO}_{2}$ : sulphur dioxide. ${ }^{\#}$ : adjusted for cubic trend, temperature, weekend, Christmas holidays, first order autocorrelation. Analysis period November 4, 1996-March 30, 1997 (147 days). 
Table 8.-Effect estimates ${ }^{\#}$ for the association between the prevalence of respiratory symptoms and particulate air pollution and $\mathrm{NO}_{2}$ (odds ratios (OR) and 95\% confidence intervals $(\mathrm{Cl})$ are expressed for an increase of one interquartile range (IQR))

\begin{tabular}{|c|c|c|c|c|c|c|c|c|c|}
\hline & \multicolumn{3}{|c|}{ Same day } & \multicolumn{3}{|c|}{ 5-day mean } & \multicolumn{3}{|c|}{ 14-day mean } \\
\hline & IQR & OR & CI & IQR & OR & CI & IQR & OR & $\mathrm{CI}$ \\
\hline \multicolumn{10}{|c|}{$\begin{array}{l}\text { Attack of shortness of breath } \\
\text { and wheezing }\end{array}$} \\
\hline NC0.01-0.1 & 15000 & 1.01 & $0.91-1.12$ & 10000 & 1.08 & $0.96-1.21$ & 7700 & 1.26 & $1.08-1.48$ \\
\hline $\mathrm{MC} 0.01-2.5$ & 28 & 0.99 & $0.89-1.10$ & 26 & 1.02 & $0.91-1.14$ & 20 & 1.13 & $1.02-1.26$ \\
\hline $\mathrm{NO}_{2}$ & 22 & 1.03 & $0.95-1.11$ & 16 & 1.06 & $0.99-1.14$ & 12 & 1.08 & $1.00-1.16$ \\
\hline \multicolumn{10}{|c|}{$\begin{array}{l}\text { Waking up with breathing } \\
\text { problems }\end{array}$} \\
\hline NC $0.01-0.1$ & 15000 & $1.04^{\circ}$ & $0.96-1.13$ & 10000 & 1.09 & $0.99-1.19$ & 7700 & 1.26 & $1.13-1.41$ \\
\hline $\mathrm{MC} 0.01-2.5$ & 28 & $1.03^{\circ}$ & $0.96-1.10$ & 26 & 1.16 & $1.06-1.25$ & 20 & 1.15 & $1.06-1.24$ \\
\hline $\mathrm{NO}_{2}$ & 22 & $1.07^{\circ}$ & $1.01-1.13$ & 16 & 1.10 & $1.04-1.15$ & 12 & 1.12 & $1.07-1.18$ \\
\hline \multicolumn{10}{|c|}{ Shortness of breath } \\
\hline NC0.01-0.1 & 15000 & 0.98 & $0.90-1.06$ & 10000 & 1.09 & $0.99-1.19$ & 7700 & 1.24 & $1.11-1.40$ \\
\hline $\mathrm{MC} 0.01-2.5$ & 28 & 1.04 & $0.96-1.13$ & 26 & 1.05 & $0.96-1.15$ & 20 & 1.03 & $0.94-1.12$ \\
\hline $\mathrm{NO}_{2}$ & 22 & 1.00 & $0.94-1.06$ & 16 & 1.05 & $0.99-1.11$ & 12 & 1.11 & $1.05-1.17$ \\
\hline \multicolumn{10}{|l|}{ Phlegm } \\
\hline NC $0.01-0.1$ & 15000 & 1.01 & $0.94-1.09$ & 10000 & 1.11 & $1.02-1.21$ & 7700 & 1.11 & $0.99-1.25$ \\
\hline $\mathrm{MC} 0.01-2.5$ & 28 & 1.05 & $0.98-1.13$ & 26 & 1.10 & $1.01-1.19$ & 20 & 1.06 & $0.97-1.15$ \\
\hline $\mathrm{NO}_{2}$ & 22 & 1.05 & $0.99-1.11$ & 16 & 1.09 & $1.04-1.15$ & 12 & 1.05 & $1.00-1.11$ \\
\hline \multicolumn{10}{|l|}{ Cough } \\
\hline $\mathrm{NC} 0.01-0.1$ & 15000 & 1.07 & $0.98-1.16$ & 10000 & 1.17 & $1.07-1.28$ & 7700 & 1.20 & $1.06-1.35$ \\
\hline $\mathrm{MC} 0.01-2.5$ & 28 & 1.07 & $0.99-1.17$ & 26 & 1.04 & $0.95-1.13$ & 20 & 1.01 & $0.92-1.10$ \\
\hline $\mathrm{NO}_{2}$ & 22 & 1.03 & $0.97-1.09$ & 16 & 1.06 & $1.00-1.12$ & 12 & 1.09 & $1.03-1.15$ \\
\hline
\end{tabular}

NC: number concentration of particles (numbers represent diameter of particles in $\mu \mathrm{m}$ ); MC: mass concentration of particles (numbers represent diameter of particles in $\mu \mathrm{m}$ ); $\mathrm{NO}_{2}$ : nitrogen dioxide. ${ }^{\#}$ : adjusted for cubic trend, temperature, weekend, Christmas holidays, first order autocorrelation; ": for the symptom "waking up with breathing problems" the effect of the concentration of pollutants on the previous day was estimated.

\section{Interpretation of the results with respect to air pollutants}

Particulate combustion emissions have the size of airborne fine particles, whereas the larger particles, also referred to as coarse particles, are mostly of geogenic origin and therefore probably less toxic [2, 36, 37]. Recent studies postulated that the ultrafine particles might have an independent effect [14, 38]. In adult asthmatics, larger decreases in PEF were observed in association with ultrafine particle number concentration compared to PM2.5 or PM10 [13-15]. In contrast, two studies on children with asthmatic symptoms showed no stronger effects of ultrafine particles than other particulate exposure $[39,40]$. The present study found evidence of independent effects of fine and ultrafine particles.

The gases $\mathrm{NO}_{2}$ and $\mathrm{CO}$ were highly correlated with ultrafine particles, and showed similar results as the ultrafine particles in the majority of the analyses. $\mathrm{SO}_{2}$ was highly correlated with fine particle mass and the results corresponded more with fine particle mass. This is consistent with ultrafine particles, $\mathrm{NO}_{2}$ and $\mathrm{CO}$ being emitted primarily by vehicle traffic, while only a small fraction of the $\mathrm{SO}_{2}$ concentration originates from this source.

\section{Limitations}

The sensitivity of the results was investigated with several approaches. The elimination of single covariates did not change the effects of the pollutants essentially. Modification of the composition of the sample, excluding the participants who showed no variation in the use of the respective medication (onehalf), resulted in higher effect estimates. Including smokers in the regression analysis, led to slightly reduced effects. To allow for longer time patterns of temperature, 3-day running means of temperature were included in the models, instead of daily temperature terms. The effect estimates were comparable to those presented here. The regression results of the air pollution models did not change substantially, when considering trend as a nonparametric, instead of a cubic function.

The study population was not uniform with respect to the diagnosis. This is unlikely to have introduced confounding since the participants served as their own controls in the statistical analyses. Given that the panel was heterogeneous, the association with ultrafine number concentrations and fine particle mass concentrations was checked in the subgroup of participants who had doctor-diagnosed asthma $(n=37)$. The results showed lower effects for inhaled short-acting $\beta_{2}$-agonists and higher effects for inhaled corticosteroids. This might be explained by the fact that this subgroup comprised the more severely affected asthmatics, who might start using their anti-inflammatory medication more readily. The healthier participants might tend to vary their inhaled short-acting $\beta_{2}$-agonist use in association with higher air pollution levels. The effect of air pollution on the 

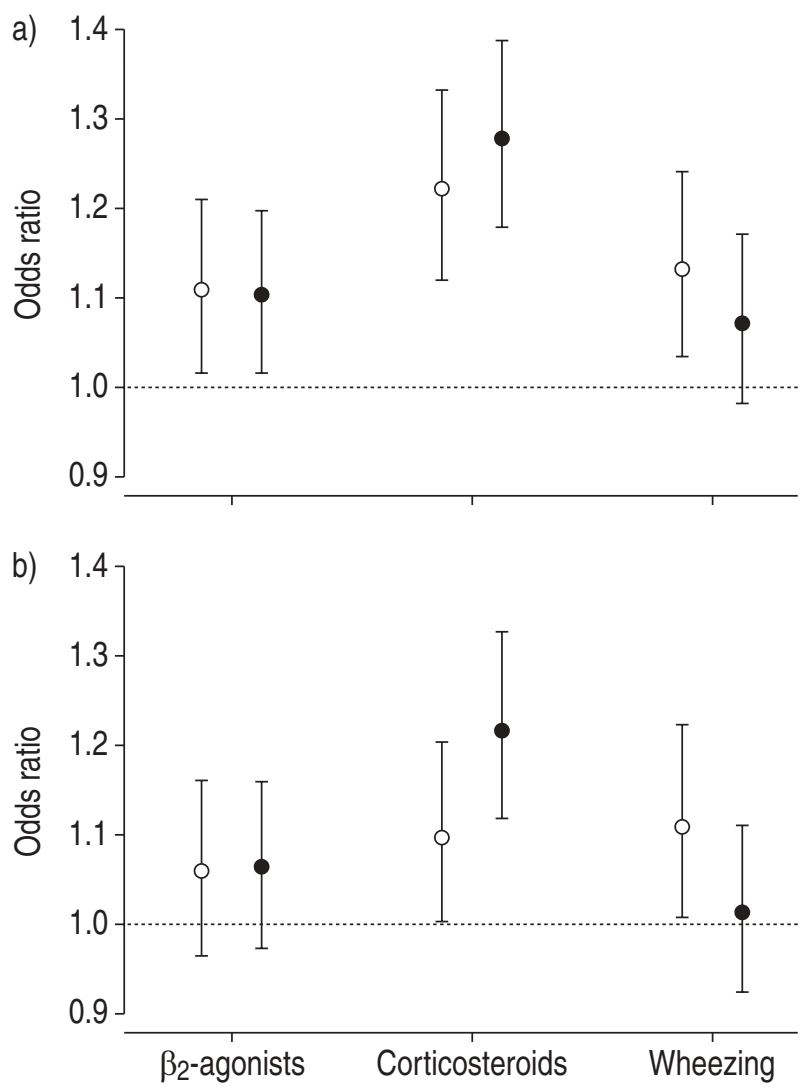

Fig. 4.-Comparison of the effect estimates of the 5-day means of fine (O) and ultrafine $(\bigcirc)$ particles in a) single and b) twopollutant models for prevalence of inhaled short-acting $\beta_{2}$-agonist use, corticosteroid use and wheezing.

symptom wheezing was higher in the asthma-diagnosed participants than in the participants who had only reported asthma symptoms. The evidence on susceptibility of the asthmatics regarding air pollution is not consistent. In the PEACE study [9], children with different health conditions did not show differences in the effect of air pollution on respiratory health. On the other hand, BoEzen et al. [41] reported higher effects of air pollution in children with elevated serum immunoglobulin E levels and bronchial hyperresponsiveness than in children without this condition. PETERs et al. [11] showed a stronger decrease in PEF in medicated than in nonmedicated children.

The incidence of short-acting $\beta_{2}$-agonist and corticosteroid use was analysed. Since the daily incidence rate was very low (fig. 1), no effects could be detected. The present authors conclude that the effects are a combination of prolonged and additional intake of the medication.

It was assumed that the personal exposures could be characterised using the measurements of one fixed measurement site. Since misclassification of the exposure is independent of the medication use, it is likely to be nondifferential, and therefore it may have caused an underestimation of the effect. It was assumed that at least the variation over time is comparable across the city, which has been shown for PM2.5 and might also be true for ultrafine particles [42].
Days when persons stayed outside the city were excluded from the analyses to avoid misclassification of exposure. Sources of pollution that may have affected the individual exposure on any other day were not assessed. This could have resulted in an underestimation of the effect.

The relationship between treatment and air pollution needs to be viewed with caution, as recording of medication is not accurate. It is likely, that participants made mistakes in their regular evening recordings of medication and dosage. It appears unlikely, that this occurred in association with the pollutants, but random misclassification resulting in underestimation may have occurred.

The generalisability of the results may be restricted to Erfurt, because of the varying composition of particles caused by different sources and meteorology and due to region-dependent asthma diagnoses and treatment.

\section{Conclusions}

The results suggest that reported inhaled asthma medication use and asthma symptoms increase in association with ultrafine and fine particulate air pollution and with gaseous pollutants, such as nitrogen dioxide, in adults in Erfurt, Germany.

\section{References}

1. Pope A, Dockery D. Epidemiology of particle effects. In: Holgate S, Samet J, Koren H, Maynard R, eds. Air Pollution and Health. London, Academic Press, 1999; pp. 673-705.

2. Pope CA III. Epidemiology of fine particulate air pollution and human health: biologic mechanisms and who's at risk? Environ Health Perspect 2000; 108: Suppl. 4, 713-723.

3. Dockery DW, Pope CA III. Acute respiratory effects of particulate air pollution. Annu Rev Public Health 1994; 15: 107-132.

4. Pope CA III, Dockery DW. Acute health effects of PM10 pollution on symptomatic and asymptomatic children. Am Rev Respir Dis 1992; 145: 1123-1128.

5. Pope CA III, Dockery DW, Spengler JD, Raizenne ME. Respiratory health and PM10 pollution. A daily time series analysis. Am Rev Respir Dis 1991; 144: 668674.

6. Hoek G, Dockery DW, Pope CA III, Neas L, Roemer $\mathrm{W}$, Brunekreef B. Association between PM10 and decrements in peak expiratory flow rates in children: reanalysis of data from five panel studies. Eur Respir $J$ 1998; 11: 1307-1311.

7. Roemer W, Hoek G, Brunekreef B. Effect of ambient winter air pollution on respiratory health of children with chronic respiratory symptoms. Am Rev Respir Dis 1993; 147: 118-124.

8. Peters A, Dockery DW, Heinrich J, Wichmann HE. Short-term effects of particulate air pollution on respiratory morbidity in asthmatic children. Eur Respir J 1997; 10: 872-879.

9. Roemer W, Hoek G, Brunekreef B. Pollution effects on asthmatic children in Europe, the PEACE study. Clin Exp Allergy 2000; 30: 1067-1075. 
10. Silverman F, Hosein HR, Corey P, Holton S, Tarlo SM. Effects of particulate matter exposure and medication use on asthmatics. Arch Environ Health 1992; 47: 51-56.

11. Peters A, Dockery DW, Heinrich J, Wichmann HE. Medication use modifies the health effects of particulate sulfate air pollution in children with asthma. Environ Health Perspect 1997; 105: 430-435.

12. Delfino RJ. Symptoms in pediatric asthmatics and air pollution: differences in effects by symptom severity, anti-inflammatory medication use and particulate averaging time. Environ Health Perspect 1998; 106: 751-761.

13. Wichmann HE, Peters A. Epidemiological evidence of the effects of ultrafine particle exposure. Philos Trans $R$ Soc Lond B Biol Sci 2000; 2000: 2751-2769.

14. Peters A, Wichmann HE, Tuch T, Heinrich J, Heyder J. Respiratory effects are associated with the number of ultrafine particles. Am J Respir Crit Care Med 1997; 155: 1376-1383.

15. Penttinen $\mathrm{P}$, Timonen KL, Tiittanen $\mathrm{P}$, Mirme A, Ruuskanen J, Pekkanen J. Ultrafine particles in urban air and respiratory health among adult asthmatics. Eur Respir J 2001; 17: 428-435.

16. Wichmann HE, Spix C, Tuch T, et al. Daily mortality and fine and ultrafine particles in Erfurt, Germany. Part I: role of particle number and particle mass. Res Rep Health Eff Inst 2000; 98: 5-86.

17. Burney PG, Luczynska C, Chinn S, Jarvis D. The European Community Respiratory Health Survey. Eur Respir J 1994; 7: 954-960.

18. Richter K, Heinrich J, Bischof W, et al. Innenraumfaktoren und Asthma bronchiale in Hamburg und Erfurt als Teil der INGA-Sudie. Studienziele und Methoden. Allergologie 1999; 22: 14-26.

19. Tuch T, Brand P, Wichmann HE, Heyder J. Variation of particle number and mass concentrations in various size ranges of ambient aerosols in eastern Germany. Atmos Environ 1997; 31: 4193-4197.

20. Tuch T, Mirme A, Tamm E, et al. Comparison of two particle-size spectrometers for ambient aerosol measurements. Atmos Environ 2000; 34: 139-149.

21. Katsouyanni K, Schwartz J, Spix C, et al. Short term effects of air pollution on health: A European approach using epidemiologic time series data: The APHEA protocol. J Epidemiol Community Health 1996; 50: S12-S18.

22. Liang KY, Zeger S. Longitudinal data analysis using generalized linear models. Biometrika 1986; 73: 13-22.

23. Zeger SL, Liang KY, Albert PS. Models for longitudinal data: a generalized estimating equation approach. Biometrics 1988; 44: 1049-1060 (published erratum appears in Biometrics 1989; 45:347).

24. Brumback BA, Schwartz J, Neas LM, Stark PC, Burge HA. Transitional regression models, with application to environmental time series. J Am Stat Assoc 2000; 95: 16-28.

25. Schwartz J, Wypij D, Dockery D, et al. Daily diaries of respiratory symptoms and air pollution: methodological issues and results. Environ Health Perspect 1991; 90: 181-187.

26. Pope CA III, Schwartz J. Time series for the analysis of pulmonary health data. Am J Respir Crit Care Med 1996; 154: 229-233.

27. Dusseldorp A, Kruize H, Brunekreef B, Hofschreuder $P$, de Meer G, van Oudvorst AB. Associations of PM10 and airborne iron with respiratory health of adults living near a steel factory. Am J Respir Crit Care Med 1995; 152: 1932-1939.

28. Gielen $\mathrm{MH}$, van der Zee SC, van Wijnen $\mathrm{JH}$, van Steen CJ, Brunekreef B. Acute effects of summer air pollution on respiratory health of asthmatic children. Am J Respir Crit Care Med 1997; 155: 2105-2108.

29. Hiltermann TJ, Stolk J, van der Zee SC, et al. Asthma severity and susceptibility to air pollution. Eur Respir $J$ 1998; 11: 686-693.

30. Segala C, Fauroux B, Just J, Pascual L, Grimfeld A, Neukirch F. Short-term effect of winter air pollution on respiratory health of asthmatic children in Paris. Eur Respir J 1998; 11: 677-685.

31. van der ZS, Hoek G, Boezen HM, Schouten JP, van Wijnen JH, Brunekreef B. Acute effects of urban air pollution on respiratory health of children with and without chronic respiratory symptoms. Occup Environ Med 1999; 56: 802-812.

32. van der Zee SC, Boezen MH, Schouten JP, van Wijnen $\mathrm{JH}$, Brunekreef B. Acute effects of air pollution on respiratory health of $50-70 \mathrm{yr}$ old adults. Eur Respir J 2000; 15: 700-709.

33. Roemer W, Hoek G, Brunekreef B, Haluszka J, Kalandidi A, Pekkanen J. Daily variations in air pollution and respiratory health in a multicentre study: the PEACE project. Pollution Effects on Asthmatic Children in Europe. Eur Respir J 1998; 12: $1354-1361$.

34. Neukirch F, Segala C, Le Moullec Y, Korobaeff M, Aubier M. Short-term effects of low-level winter pollution on respiratory health of asthmatic adults. Arch Environ Health 1998; 53: 320-328.

35. Roemer W, Hoek G, Brunekreef B, et al. PM10 elemental composition and acute respiratory health effects in European children (PEACE project). Pollution Effects on Asthmatic Children in Europe. Eur Respir $J$ 2000; 15: 553-559.

36. Schwartz J, Dockery DW, Neas LM. Is daily mortality associated specifically with fine particles? J Air Waste Manag Assoc 1996; 46: 927-939.

37. Schwartz J, Norris G, Larson T, Sheppard L, Claiborne C, Koenig J. Episodes of high coarse particle concentrations are not associated with increased mortality. Environ Health Perspect 1999; 107: 339-342.

38. Seaton A, MacNee W, Donaldson K, Godden D. Particulate air pollution and acute health effects. Lancet 1995; 345: 176-178.

39. Tiittanen P, Timonen KL, Ruuskanen J, Mirme A, Pekkanen J. Fine particulate air pollution, resuspended road dust and respiratory health among symptomatic children. Eur Respir J 1999; 13: 266-273.

40. Pekkanen J, Timonen KL, Ruuskanen J, Reponen A, Mirme A. Effects of ultrafine and fine particles in an urban air on peak expiratory flow among children with asthmatic symptoms. Environ Res 1997; 74: 24-33.

41. Boezen HM, van der Zee SC, Postma DS, et al. Effects of ambient air pollution on upper and lower respiratory symptoms and peak expiratory flow in children. Lancet 1999; 353: 874-878.

42. Janssen NA, de Hartog JJ, Hoek G, et al. Personal exposure to fine particulate matter in elderly subjects: relation between personal, indoor, and outdoor concentrations. J Air Waste Manag Assoc 2000; 50: 1133-1143. 